\title{
GAMBARAN PENGETAHUAN WANITA USIA SUBUR (WUS) TENTANG KONTRASEPSI IUD \\ DI WILAYAH KERJA PUSKESMAS DANUREJAN 1 KOTA YOGYAKARTA
}

\author{
Dechoni Rahmawati $^{1 *}$, Siti Solikhah ${ }^{2}$
}

\begin{abstract}
*1,2Program Studi Kebidanan Stikes Jenderal Achmad Yani Yogyakarta, Jl. Ringroad Barat ambarketawang, Gamping, sleman, Telp.(02744342000), Email:dechoni.aris@gmail.com
\end{abstract}

\begin{abstract}
Background: The high birth rate in Indonesian is one of the major problems and requires special attention, the population increased in 2015 amounted to $255,461,686$ people, the population in Indonesian is fourth after China, India, and Unite States (Depkes Indonesian, 2015). Data from the health service DIY, acceptors of IUD is the the lowest number in Yogyakarta, located in community health service Danurejan I as many as 215 acceptor

Objectives: The aim of this study is to know the knowledge of women fertile about contraception in community health center Danurejan 1 Yogyakarta.

Methods: Research design used was a descriptive quantitative research. The sampling technique used purposive sampling with the total of responden as many as 73. Data analysis used analysis univariat.

Result: the result of this research shows that based on level knowledge WUS about contraception of IUD be categorized the level of knowledge as good is 50 responden $(68.5 \%)$. In the category of enough of knowledge was 21 respondents ( $28.8 \%$ ) and lack of knowledge as lack is 2 respondents $(2.7 \%)$.

Conclusion: Based on the result of this research which had done showed that WUS knowledge about IUD contraception in community health center Danurejan 1 Yogyakarta mostly of responden having good knowledge as many as 50 responden (68.5\%)
\end{abstract}

Keywords: Knowledge, Women Fertile (WUS), IUD Contraception

\section{PENDAHULUAN}

Tingginya angka kelahiran di Indonesia merupakan salah satu masalah besar dan memerlukan perhatian khusus dalam penanganannya, laju peningkatan penduduk pada tahun 2015 sebesar 255.461.686 jiwa, jumlah penduduk Indonesia berada pada urutan keempat terbesar setelah Cina, India, Amerika Serikat. $^{1}$

Kematian Bayi dan Balita di Indonesia dalam 5 tahun terakhir. Berdasarkan data World Health Statistics tahun 2016, penggunaan kontrasepsi telah meningkat di banyak bagian dunia, terutama di Asia dan Amerika Latin, tetapi terus menjadi rendah di
sub-Sahara Afrika. Secara global, penggunaan kontrasepsi modern telah meningkat sedikit, dari 54\% pada tahun 1990 menjadi 57,4\% pada tahun 2015.

Berdasarkan persentase peserta $\mathrm{KB}$ baru di Indonesia di antaranya, akseptor KB Kondom sebanyak 5,47\%, Pil sebanyak $26,36 \%$, Suntik sebanyak 49,93\%, IUD sebanyak 6,81\%, Implan sebanyak 9,63\%, MOW sebanyak 1,64\%, MOP sebanyak $0,16 \%$. Persentase perserta KB aktif di Indonesia yaitu akseptor KB Kondom sebanyak 3,16\%, Pil sebanyak 23,60\%, Suntik sebanyak $47,78 \%$, IUD sebanyak 10 , $73 \%$, Implan sebanyak 10,58\%, MOW sebanyak 3,49\%, MOP sebanyak 0,65\%. Dari 
data tersebut KB IUD dan Implan merupakan MKJP yang dapat digunakan oleh wanita usia subur yang masih mempunyai program ingin memiliki anak, sehingga apabila setelah menggunakan kotrasepsi dapat segera kembali kesuburannya, kontrasepsi yang kurang diminati oleh akseptor KB adalah IUD. $^{2}$

Provinsi DIY pencapaian peserta KB aktif menurut jenis kontrasepsi yaitu IUD sebanyak 100.704 akseptor (70,0\%), MOP sebanyak 629 akseptor (0,4\%), MOW sebanyak 2.824 akseptor (2,0\%), Implan 6.986 akseptor (4,9\%), Kondom sebanyak 2.366 akseptor (1,6\%), Suntik sebanyak 23.183 akseptor (16,81\%), Pil sebanyak 5.170 akseptor (3,6\%). Peserta KB baru IUD sebanyak 8.545 akseptor (25,8\%), MOP 181 akseptor (0,5\%), MOW 679 akseptor (2,1\%), Implan 2.959 akseptor (8,9\%), Kondom sebanyak 1.521 akseptor (37,3\%), Suntik sebanyak 16,324 akseptor (49,3\%), Pil 2.895 akseptor (8,7\%). Akseptor KB aktif IUD di Kabupaten Kulon Progo sebanyak 13.339 akseptor (25,3\%), Kabupaten Bantul sebanyak 28.406 akseptor (23,6\%), Kabupaten Gunung Kidul sebanyak 13.111 akseptor (14,2\%), Kabupaten Sleman sebanyak 35.351 akseptor (27,7\%), dan Kabupaten Kota Yogyakarta sebanyak 10.317 akseptor ( 29,8\%). Akseptor KB baru IUD di Kabupaten Kulon Progo yaitu sebanyak 798 akseptor (22,1\%), Kabupaten Bantul sebanyak 3.839 akseptor (27,7\%), Kabupaten Gunung Kidul sebanyak 1.399 akseptor (19,9\%), Kabupaten Sleman sebanyak 1.564 akseptor(23,5\%), dan Kabupaten Kota Yogyakarta sebanyak 945 akseptor (49,0\%). Dari data tersebut jumlah akseptor KB IUD di Kabupaten Kota Yogyakarta merupakan jumlah yang paling rendah dibandingkan akseptor KB IUD di Kabupaten lain. ${ }^{3}$

Kabupaten Kota Yogyakarta mempunyai 18 kecamatan dengan jumlah peserta KB aktif sebanyak 36.360 akseptor. KB IUD sebanyak 11.599 akseptor (31,90\%), MOP sebanyak 231 akseptor (0,64\%), MOW sebanyak 2.258 akseptor (6,21\%), Implan sebanyak 1.118 akseptor 3,07\%), Kondom sebanyak 5.905 akseptor (16,24\%), Suntik sebanyak 11.380 akseptor (31,30\%), Pil sebanyak 3.869 akseptor (10,64\%). Jumlah peserta KB baru sebanyak 1.656 akseptor. KB IUD sebanyak 787 akseptor (47,55\%), MOP sebanayak 2 akseptor $0,12 \%$ ), MOW sebanyak 48 akseptor (2,90\%), Implan sebanyak 45 akseptor (2,72\%), Kondom sebanyak 87 akseptor (5,26\%), Suntik sebanyak 573 akseptor 34,62\%), dan Pil sebanyak 113 akseptor (6,83\%). Peserta KB IUD di Kecamatan Danurejan adalah 462 akseptor, merupakan angka terendah dari pada kecamatan lainnya. ${ }^{3}$

\section{BAHAN DAN CARA PENELITIAN}

Jenis penelitian ini merupakan penelitian deskriptif kuantitatif. ${ }^{4}$ Populasi pada penelitian ini adalah WUS yang belum menggunakan kontrasepsi di wilayah kerja 
Puskesmas Danurejan 1 Kota Yogyakarta dengan jumlah 266 wanita usia subur. ${ }^{5}$

Pengambilan sampel diambil dengan teknik Nonprobability sampling dilaksanakan secara Purposive sampling. Nonprobability sampling adalah teknik pengambilan sampel yang tidak memberikan peluang yang sama bagi setiap anggota populasi untuk dipilih menjadi anggota sampel yaitu teknik penentuan sampel berdasarkan kebetulan. Puposive Sampling yaitu tekhnik penentuan sampel dengan pertimbangan tertentu, sampel diambil sesuai dengan kriteria berdasarkan ciri-ciri yang sudah ditentukan dan cocok sebagai sumber data. ${ }^{6}$ Analisa data dilakukan secara univariate untuk mendeskripsikan variabel penelitian guna memeroleh gambaran karakteristik variabel. ${ }^{7}$

\section{HASIL DAN PEMBAHASAN}

Berdasarkan Tabel 1 menunjukkan bahwa karakteristik responden berdasarkan umur semua berada pada kelompok umur 2035 tahun sebanyak 73 responden (100\%), sebagian besar pendidikan terakhir adalah SMA sebanyak 54 responden $(74,0 \%)$, dan sebagian besar bekerja sebagai IRT sebanyak 51 responden (69,9\%).

Berdasarkan tabel 2 menunjukkan bahwa tingkat pengetahuan WUS tentang kontrasepsi IUD sebagian besar mempunyai tingkat pengetahuan baik sebanyak 50 responden $(68.5 \%)$.
Tabel 1. Distribusi Frekuensi Responden di

Puskesmas Danurejan I Kota Yogyakarta

\begin{tabular}{|c|c|c|}
\hline Karakteristik Responden & $\mathbf{F}$ & $(\%)$ \\
\hline \multicolumn{3}{|l|}{ Umur: } \\
\hline 1. $<20$ tahun & 0 & 0 \\
\hline 2. 20-35 tahun & 73 & 100.0 \\
\hline 3. $>35$ tahun & 0 & 0 \\
\hline Jumlah & 73 & 100.0 \\
\hline \multicolumn{3}{|l|}{ Pendidikan Terakhir: } \\
\hline 1. SD & 3 & 4.1 \\
\hline 2. SMP & 7 & 9.6 \\
\hline 3. SMA & 54 & 74.0 \\
\hline 4. Perguruan Tinggi & 9 & 12.3 \\
\hline Jumlah & 73 & 100.0 \\
\hline \multicolumn{3}{|l|}{ Pekerjaan: } \\
\hline 1. IRT & 51 & 69.9 \\
\hline 2. Swasta & 9 & 12.3 \\
\hline 3. Wiraswasta & 10 & 13.7 \\
\hline 4. PNS & 2 & 2.7 \\
\hline 5. Buruh & 1 & 1.4 \\
\hline Jumlah & 73 & 100.0 \\
\hline
\end{tabular}

Tabel 2. Gambaran Pengetahuan WUS Tentang Kontrasepsi IUD di Wilayah Kerja Puskesmas Danurejan 1 Kota Yogyakarta Tahun 2017

\begin{tabular}{ccc}
\hline Kategori & F & $\%$ \\
\hline Baik & 50 & 68.5 \\
Cukup & 21 & 28.8 \\
Kurang & 2 & 2.7 \\
\hline & 73 & 100.0
\end{tabular}

Sumber: Data Primer, (2017) 
Tabel 3. Distribusi frekuensi Pengetahuan WUS Tentang Kontrasepsi IUD Berdasarkan Karakteristik

\begin{tabular}{llccc}
\hline $\begin{array}{l}\text { Karakteristik } \\
\text { Responden }\end{array}$ & \multicolumn{3}{c}{ Tingkat Pengetahuan } \\
\hline \multicolumn{1}{l}{ Umur: } & Baik & Cukup & Kurang \\
\hline 1. & $<20$ tahun & - & - & - \\
\hline 2. & $\begin{array}{l}20-35 \\
\text { tahun }\end{array}$ & $50(68.5 \%)$ & $21(28.8 \%)$ & $2(2.7 \%)$ \\
\hline 3. & $>35$ \\
& tahun & & & \\
\hline
\end{tabular}

\section{Pendidikan}

Terakhir:

\begin{tabular}{lccc}
\hline 1. SD & $1(1.4 \%)$ & $1(1.4 \%)$ & $1(1.4 \%)$ \\
\hline 2. SMP & $7(9.6 \%)$ & $0(0 \%)$ & $0(0 \%)$ \\
\hline 3. SMA & $35(47.9 \%)$ & $18(24.7 \%)$ & $1(1.4 \%)$ \\
\hline $\begin{array}{c}\text { 4. Perguruan } \\
\text { Tinggi }\end{array}$ & $7(9.6 \%)$ & $2(2.7 \%)$ & $0(0 \%)$ \\
\hline
\end{tabular}

\section{Pekerjaan:}

\begin{tabular}{lccc}
\hline 1. IRT & $34(46.6 \%)$ & $16(21.9 \%)$ & $1(1.4 \%)$ \\
\hline 2. Swasta & $9(12.3 \%)$ & $0(0 \%)$ & $0(0 \%)$ \\
\hline 3. Wiraswasta & $6(8.2 \%)$ & $3(4.1 \%)$ & $1(1.4 \%)$ \\
\hline 4. PNS & $1(1.4 \%)$ & $1(1.4 \%)$ & $0(0 \%)$ \\
\hline 5. Buruh & $0(0 \%)$ & $1(1.4 \%)$ & $0(0 \%)$
\end{tabular}

Sumber: Data Primer, (2017)

Berdasarkan tabel 3 menunjukkan bahwa tingkat pengetahuan WUS tentang kontrasepsi IUD di wilayah kerja Puskesmas Danurejan 1 Kota Yogyakarta berdasarkan karakteristik umur yang paling banyak berusia 20-35 tahun dengan tingkat pengetahuan baik sebanyak 50 responden (68.5\%).

Tingkat pengetahuan WUS tentang kontrasepsi IUD di wilayah kerja Puskesmas Danurejan 1 Kota Yogyakarta berdasarkan karakteristik pendidikan terakhir paling banyak pendidikan SMA dengan tingkat pengetahuan baik sebanyak 35 responden (47.9\%).
Tingkat pengetahuan WUS tentang kontrasepsi IUD di wilayah kerja Puskesmas Danurejan 1 Kota Yogyakarta berdasarkan karakteristik pekerjaan paling banyak bekerja sebagai IRT dengan tingkat pengetahuan baik sebanyak 34 responden (46.6\%).

Berdasarkan analisis hasil penelitian yang dilakukan di Puskesmas Danurejan 1 Kota Yogyakarta dengan jumlah 73 responden diketahui bahwa sebagian besar responden merupakan WUS dengan tingkat pengetahuan tentang kontrasepsi IUD kategori baik sebanyak 50 responden $(68.5 \%)$.

Sedangkan hasil penelitian yang dilakukan oleh Rindiarti, dkk (2013) sebagian besar berpengetahuan kurang sebanyak 15 responden $(50 \%)$, berpengetahuan cukup sebanyak 10 responden (33.3\%), dan berpengetahuan baik sebanyak 5 (16.7\%). Dalam hal ini menunjukkan adanya perbedaan tingkat pengetahuan dengan penelitian lain yang sudah dilakukan. ${ }^{8}$

Tingkat Pengetahuan WUS Tentang Kontrasepsi IUD berdasarkan umur menunjukkan bahwa tingkat pengetahuan tentang kontrasepsi IUD semua berada pada kelompok umur 20-35 tahun sebanyak 73 responden (100\%), dengan pengetahuan baik sebanyak 50 responden (68.5\%).

Hasil penelitian ini sesuai dengan Notoadmodjo (2014) bahwa usia seseorang akan mempengaruhi tingkat pengetahuannya. Hal ini dihubungkan dengan beberapa faktor lain yang 
mempengaruhi pengetahuan antara lain informasi yang diperoleh dari tenaga kesehatan, media massa atau buku-buku. Semakin cukup umur, tingkat kematangan dan kekuatan sesorang akan lebih matang dalam berfikir dan bekerja, termasuk pengetahuan tentang kesehatan. Semakin bertambahnya umur seseorang maka semakin bertambah keinginan dan pengetahuan. $^{9}$

Berdasarkan tingkat pengetahuan responden tentang kontrasepsi IUD salah satu faktor yang mempengaruhi yaitu pendidikan, hasil penelitian menunjukkan bahwa sebagian besar tingkat pengetahuan tentang kontrasepsi IUD berada pada responden yang berpendidikan SMA dengan pengetahuan baik sebanyak 35 (47.9\%) dan sangat sedikit berpendidikan SD dengan pengetahuan kurang sebanyak 1 responden $(1.4 \%)$.

Hasil penelitian ini sesuai dengan Budiman dan Riyanto (2014) bahwa pendidikan berarti bimbingan yang diberikan seseorang terhadap perkembangan orang lain menuju ke arah cita-cita tertentu sehingga menentukan manusia dalam berbuat dan mengisi kehidupannya sehingga pada akhirnya mencapai keselamatan dan kebahagiaan. Pendidikan diperlukan untuk mendapat informasi misalnya hal-hal yang dapat menunjang kesehatan sehingga dapat meningkatkan kualitas hidup. ${ }^{10}$

Pada umumnya semakin tinggi pendidikan seseorang maka semakin mudah menerima informasi karena tingkat pendidikan WUS sebagian besar berpendidikan SMA yang pengetahuannya baik. Namun perlu ditekankan bahwa seseorang yang berpendidikan rendah tidak berarti mutlak berpengetahuan rendah pengetahuannya. Karena pengetahuan dapat diperoleh dari pendidikan formal maupun informal.

Tingkat pengetahuan responden tentang kontrasepsi IUD berdasarkan pekerjaan menunjukkan bahwa sebagian besar berada pada kelompok Ibu Rumah Tangga (IRT) dengan pengetahuan baik sebanyak 34 responden (46.6\%). Hal ini tidak sesuai dengan teori Notoadmodjo (2014) bahwa seseorang dengan status ekonomi yang baik akan lebih mudah mendapatkan informasi karena adanya status ekonomi yang baik akan mempunya fasilitas yang baik, karena walaupun WUS mempunyai pekerjaan IRT mereka tetap berbagi informasi dan sering mengikuti posyandu. ${ }^{9}$

Dalam penelitian ini dilakukan beberapa wawancara untuk mengetahui alasan mengapa sebagian besar WUS tidak memilih kontrasepsi IUD untuk digunakan sebagai alat mencegah kehamilan pada waktu yang akan datang sedangkan sebagian besar WUS berpengetahuan baik, dikarenakan pernah mendengar pengalaman dari orang lain misalnya IUD terlepas, perdarahan, kram perut, ketidakcocokan dalam menggunakan IUD, sakit saat berhubungan seksual. Meskipun hal ini belum 
dapat dibuktikan oleh responden, namun seringkali bahan pembicaraan ini cukup mempengaruhi persepsi responden akan kenyamanan dalam pemakaian IUD. Hal ini sama dengan penelitian sebelumnya, bahwa dalam penelitian tersebut sebagian besar lbulbu menyiratkan perasaan kurang aman karena menurut pendapat mereka IUD adalah sebuah benda asing dimasukkan kedalam tubuh yang dapat membuat pemakainya mengalami efek samping tertentu. Hal ini dikarenakan kurangnya konseling yang perlu ditekankan mngenai kontrasepsi IUD pada tenaga kesehatan di Puskesmas untuk mengajak WUS menggunakan kontrasepsi yang paling efektif seperti IUD. Sehingga responden tidak hanya mendengar informasi yang bersifat negatif dari tetangga. Setiap tenaga kesehatan berkewajiban memberikan informasi dan motivasi yang baik dan benar tentang alat kontrasepsi kepada WUS sehingga dapat memiliki kesadaran dalam mengikuti gerakan $\mathrm{KB}$

Dalam penelitian ini pengetahuan WUS tentang kontrasepsi IUD mayoritas kategori baik sebanyak 50 responden (68.5\%), hal ini tidak sesuai dengan rencana penelitian dikarenakan keseluruhan hasil penelitian ini kurangnya pengguna KB IUD bukan di sebabkan karena rendahnya pengetahuan dari WUS tersebut.

\section{KESIMPULAN}

Berdasarkan hasil penelitian tentang Gambaran Pengetahuan Wanita Usia Subur (WUS) Tentang Kontrasepsi IUD di Wilayah Kerja Puskesmas Danurejan 1 Kota Yogyakarta Tahun 2017 dapat di buat kesimpulan sebagai berikut:

Karakteristik responden berdasarkan umur semua berada pada kelompok umur 2035 tahun sebanyak 73 responden (100\%), Pengetahuan WUS tentang kontrasepsi IUD sebagian besar responden mempunyai pengetahuan baik yaitu sebanyak 50 responden (68.5\%). tingkat pengetahuan WUS tentang kontrasepsi IUD di wilayah kerja Puskesmas Danurejan 1 Kota Yogyakarta berdasarkan karakteristik umur yang paling banyak berusia 20-35 tahun dengan tingkat pengetahuan baik sebanyak 50 responden (68.5\%).

\section{KEPUSTAKAAN}

1. Depkes RI, Profil Kesehatan Indonesia Tahun 2014. Tersedia dalam Depkes.go.id. Di akses pada 16 Desember 2016.

2. BKKBN. Laporan Kinerja Instansi Pemerintah Tahun 2015. Yogyakarta: BKKBN. 2016

3. Dinas kesehahatan DIY. Profil Kesehatan Daerah Istimewa Yogyakarta Tahun 2016. Yogyakarta: Dinas kesehatan DIY.

4. Notoadmodjo, S. IImu Prilaku Kesehatan. Jakarta: Rineka cipta. 2014

5. Hidayat, A. Metode Penelitian Kebidanan Dan Teknik Analisis Data. Jakarta: Salemba medika. 2014

6. Sugiyono. Metode Penelitian, Kuantitatif, Kualitatif, Dan R\&D. Bandung: Alfabeta. 2016 
7. Sulistyawati, A. Pelayanan Keluarga Berencana. Jakarta: Salemba medika. 2014

8. Rindiarti. Tingkat pengetahuan wanita usia subur tentang alat kontrasepsi IUD di BPRB Bina Sehat Kasihan Bantul. Karya Tulis IImiah STIKES Alma Ata Yogyakarta. 2013
9. Notoadmodjo, S. Metodologi Penelitian Kesehatan. Jakarta: Rineka cipta. 2012

10. Budiman dan Riyanto. Kapita Selekta Kuesioner, Pengetahuan dan Sikap dalam Peneitian Kesehatan. Jakarta. Salemba Medika. 2014 